\title{
La melancolía amorosa en Amistad Funesta de José Martí
}

\author{
Loving Melancholy in Amistad Funesta by José Martí
}

\author{
AINHOA SEGURA ZARIQUIEGUI \\ Tianjin Foreign Affairs University \\ China
}

(Recibido: 23-II-2OI5; aceptado: o8-OI-2OI6

Resumen. Existe una multitud de áreas temáticas desde las cuales aproximarse a la obra literaria de José Martí. En esta ocasión, se va mostrar de qué forma está impregnado el concepto de la melancolía en su novela Amistad funesta. Este análisis trata de ofrecer una nueva mirada sobre este texto gracias a la aplicación de las herramientas de la literatura comparada. Lucía Jerez se va a casar con su primo Juan, pero aparece Sol, una joven muy hermosa que hace estallar el conflicto entre los protagonistas. Tras el análisis de la historia de la melancolía en la literatura de Occidente, se comprueba cómo este concepto se mantiene arraigado en el Modernismo y, más concretamente, en esta obra de José Martí.

Palabras clave: Occidente; melancolía; literatura; Modernismo; Martí.
Abstract. There are many ways to analyze the work of José Martí. In this article it will be observed from the point of view of black bile, also named "melancholy". The novel exudes passion on every page. This text is full of sadness, love and tragedy. Lucía Jerez will marry his cousin John, but appears Sol, a beautiful young woman, while Ana is located at the gates of death. This paper intends to speak of loving black bile as a disease, but also as the beginning of the poetic inspiration. Firstly, we talk about the melancholy, and secondly, we analyze the origin and historical tracking of amorous melancholy in literature until the Modernism and particularly this work of Martí (Amistad Funesta). We try to point out the importance of the black bile as poetic energy and how the concept changes when passing through different historical moments.

Key words: Occident; melancholy; literature; Modernism; Martí.

\footnotetext{
I Para citar este artículo: Segura Zariquiegui, Ainhoa (20I7). La melancolía amorosa en Amistad funesta de José Martí. Alabe 15. [www.revistaalabe.com]

DOI: IO.I5645/Alabe2OI7.I5·3
} 


\section{Introducción}

Existen muchas formas de analizar la obra Amistad funesta del gran escritor modernista José Martí. En esta ocasión va a ser observada desde el punto de vista de la melancolía. La novela del cubano destila melancolía pasional en cada página. De ahí que la temática esté inyectada de un halo de tristeza, pasión y tragedia muy del gusto modernista de la época. Lucía Jerez va a casarse con su primo Juan, pero aparece Sol, una bellísima joven que, sin querer, se interpondrá entre la pareja, mientras Ana, joven enferma de tuberculosis, se encuentra a las puertas de la muerte. Este trabajo se propone hablar de la melancolía amorosa como enfermedad, pero también como motor de arranque de la inspiración poética. Primero se hablará de la melancolía en términos generales y se pasará, un poco más tarde, a señalar el origen y el seguimiento histórico de la melancolía amorosa en la literatura hasta llegar al Modernismo y analizar particularmente esta obra de Martí, teniendo en cuenta la importancia como impulso poético y las metamorfosis que el concepto experimenta al atravesar diferentes momentos históricos.

\section{El concepto de melancolía amorosa a lo largo de la historia literaria}

La melancolía es una noción que ha recorrido toda la historia de la de la humanidad. Se encuentra anclada al ser humano porque forma parte de él, de su esencia. En tiempos presocráticos, la bilis negra era un término que hacía referencia a enfermedades tanto mentales como físicas. De esta forma, se puede observar cómo el significado etimo-

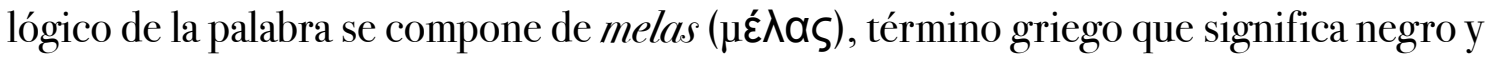
kholé (Xoגń) que quiere decir humor o bilis. La medicina griega, con Hipócrates (460 a.C.-37O a.C.) a la cabeza, entendía que al ingerir los alimentos se producían sustancias que el cuerpo debía eliminar pero si no eran expulsadas permanecían en su interior produciendo enfermedades. El humor negro o melancolía era la más dañina.

Este concepto asociado en principio sólo a la enfermedad extendió su significado. La ampliación del concepto de melancolía puede percibirse explícitamente en Sócrates, Platón y sobre todo en Aristóteles, los cuales dieron a la bilis negra un carisma diferente: el ser melancólico era un ser tocado por los dioses. Sabemos que Sócrates nunca escribió pero Platón dejó lo dicho por éste gran filósofo en varias de sus obras. En Fedro, Sócrates habla a cerca de la locura (melancolía) y la subdivide en dos: una primera, la locura como enfermedad humana, y una segunda, la locura como inspiración divina. A su vez, el filósofo divide esta inspiración divina en cuatro melancolías otorgando a cada una de ellas una divinidad: la profética (Apolo), la mística (Dioniso), la poética (las Musas), y por último, la erótica o amorosa (Afrodita y Eros): 
En efecto, frente a una locura humana -señala Carolina A. Navarrete-, cuyas causas estarían dadas por trastornos funcionales, habría una locura de origen divino la cual sería fuente para toda la humanidad de los mayores bienes. Aquí se encontrarían tres tipos de delirio: el caso de la mántica, la predicción del porvenir en estado de trance y posesión, el de los profetas que instituyeron los misterios, y el de la inspiración poética, estos delirios no serían más que otras de las tantas manifestaciones de la locura divina. El amor es también una forma de locura, la más excelsa de todas, y la que mayores bienes produce en las almas, tanto del amante como del amado (2006:2).

Los dioses se relacionaban con las personas a través de estas cuatro fuerzas que se transformaban en locura cuando habitaban en el ser humano. La locura que nos atañe y que vamos a tratar en la obra de Martí es la melancolía amorosa. Esta inspiración divina, en relación con el amor, ha tenido muchas expresiones en la medicina. El ser enamorado puede caer en la enfermedad del amor. De este hecho ya se percataron los antiguos médicos (como Galeno, el médico más importante de la época clásica, curtido en la cura de gladiadores tras las festividades romanas), los cuales reflexionaron sobre el mal de amores. Un ejemplo que ofrece Galeno es el momento en que midió el pulso de una joven con este trastorno y se dio cuenta de que estaba secretamente enamorada de un bailarín ya que cuando aparecía el muchacho, el ritmo se volvía más fuerte. Médicos bizantinos como Pablo de Egina u Oribasio fueron los primeros en describir sus síntomas: frecuencia del pulso, ojos hundidos y parpadeo continuo, tristeza, falta de apetito. Uno de los libros más importantes de la Edad Media fue el Canon de Avicena. Jackson señala que este gran médico definió así la melancolía: "Una desviación del estado natural acompañado por el miedo y una malignización de la bilis negra, en la que sus vapores suben al cerebro y asustan al paciente con su lobreguez" (I986:32). Avicena incluyó en su libro, una sección titulada «Enfermedades de la cabeza», donde hay un capítulo sobre el amor en el cual se dice que es una enfermedad mental similar a la melancolía caracterizada por la excitación continuada de la mente. Ya en el siglo XVI Robert Burton, médico inglés, cuyo tratado Anatomía de la Melancolía le haría conocido en toda Europa, incluía un capítulo entero a cerca de la melancolía amorosa.

El concepto del amor parece una noción inamovible, pero la realidad es que ha ido variando a lo largo de los siglos y eso se ve reflejado en los textos escritos. Aunque si bien, es verdad que los griegos consideraban el amor apasionado como una enfermedad, este amor, al buscar al mismo tiempo el bien y la belleza, mejoraba y embellecía de manera efectiva la totalidad de la existencia. Pero el Cristianismo transformó este amor pleno y lo escindió: "Con el ocaso de la Antigüedad desapareció la posibilidad del amor griego; el mundo escindido entre lo sensual y lo espiritual modificó el amor. No llegó a escindirlo porque el amor se mantuvo unido e independiente -afirma Földényi-, sino que sólo cambió su posición. El amor cristiano no busca una alianza del amante con los poderes terrenales, sino más bien una boda con el cielo a través del enamorado" (2008:253). Los 
occidentales somos fruto de esa escisión amorosa. El Cristianismo vuelve pecaminoso el contacto corporal, el único amor posible se convierte en el amor ágape, o el amor espiritual. Y todo esto se ve reflejado en el arte. Respecto a la literatura, se puede señalar que al ser expresión de sentimientos, la melancolía, producto de esta escisión, movilizó una parte muy importante de las temáticas artísticas de aquellas épocas. De ahí que la primera expresión literaria que afloró en España esté totalmente embebida de amor melancólico. Se trata de las jarchas, esas canciones de amor que una mujer contaba a una confidente y cuyo tema principal era el dolor melancólico por la ausencia del amado. Otra expresión de la melancolía en la literatura se encuentra en el amor cortés que Denis de Rougemont comenta en su famosa obra Amory occidente. El amor cortés nació en Provenza, en la corte de Leonor de Aquitania. Su hija, María de Champaña, continuará la obra cortesana de su madre. Andreas Capellanus, clérigo de Leonor de Aquitania, escribió De amore que viene a ser un tratado de cómo debe comportarse un caballero. EL libro se encuentra influenciado por el Ars Amandi de Ovidio, pero adaptado a los tiempos medievales. El caso es que el hombre debe estar enfermo de amor por su dama, debe sufrir y suspirar por ella: no puede dormir, ni comer, ni sentir ningún tipo de placer. Sólo el recuerdo de su pasión hace aparecer la esperanza. Roman de la Rose es el gran poema francés que codificará la compleja trama de lo que se llamará el amor cortés y se trata de una gigantesca alegoría sobre las vicisitudes por las que pasa el amante para conseguir a su amada. El mundo escindido entre lo sensual y lo espiritual se puede observar en este amor melancólico porque la dama, a pesar de ser de carne y hueso, es caracterizada con todos los rasgos de la divinidad. Podemos encontrar muchos ejemplos en obras posteriores en las que se advierte la influencia de esta escisión. Un ejemplo es la Celestina de Fernando de Rojas, obra que parodia el amor cortés manteniendo los lugares comunes. Sempronio pregunta a Calisto: “¿Tú no eres cristiano?”. A lo que contesta el joven: “¿Yo? Melibeo só, y a Melibea adoro, y en Melibea creo, y a Melibea amo" (2000:93). Calixto sufre, es un hombre enfermo que padece melancolía amorosa (o, mejor dicho, hace ver que sufre ya que nos encontramos ante una parodia). En el primer auto de la tragicomedia señala los síntomas más característicos de la enfermedad melancólica e incluso menciona al gran Galeno: "Cierra la ventana y dexa la tiniebla acompañar al triste y al desdichado la ceguedad. Mis pensamientos tristes no son dignos de luz. ¡O bienaventurada muerte aquella que deseada a los afligidos viene! ¡O si viniéssedes agora, Crato y Galeno, médicos, sentiríades mi mal!" (2000:88).

Con la influencia neoplatónica que llega de Italia, este amor, todavía medieval, se trasforma en neoplatónico. Ficino (I433-I499) fue un médico italiano del Renacimiento. Apunta Andrea Paul que era un gran experto en el tema de la curación de la melancolía: "Ficino utiliza varias páginas de su tratado para presentar una lista extensa que explica cuáles son los alimentos, las bebidas y las actividades que provocan la mala melancolía y aquellos que ayudan a contrarrestarla" (20I4:I8I). Pero la faceta más transcendente de Ficino fue la de filósofo y traductor, de hecho, tradujo varias obras clásicas, entre ellas las de Platón y las reinterpretó creando una nueva forma de concebir el arte. De ahí que fuera 
el impulsor de la filosofía neoplatónica. En su obra De amore mostraba la base del funcionamiento del amor neoplatónico. Al respecto, Földényi comenta: "De amore de Ficino es un ejemplo característico de cómo cambiaron los valores respecto al amor entrelazado con la melancolía" (2008:258). Nos encontramos en los tiempos pre-modernos del Renacimiento italiano; el amor escindido entre lo sensual y lo espiritual por el Cristianismo, mantenido en esta ruptura por los cánones medievales del amor cortés y su literatura, se van a separar un poco más: se trata de ver a la divinidad a través del amado. Pero este canto a lo divino crea desazón, produce melancolía, al encontrarnos siempre ante un ser de carne y hueso que nunca responderá al ideal divino. Por eso, los poetas neoplatónicos cantan a amadas construidas de forma artificiosa en su mente. En el Soneto X de Miguel Ángel Buonarroti podemos percibir este amor platónico: "La belleza que ves en verdad está en ella/pero crece al subir hasta un lugar mejor/y por los ojos mortales viene al alma. /Ahí divina se vuelve, honesta y bella, / pues semejante a sí es todo lo inmortal:/y ésta, no aquella, se llega hacia tus ojos". Se observa como el amado puede ver, a través de la belleza de los ojos de la persona amada, el alma, lo divino, lo inmortal. Pero este amor no deja de ser melancólico, muy al contrario, se vuelve profundamente malsano porque se instala en el campo de lo ideal: "El amor moderno no interviene en el curso del mundo ni contribuye a su configuración. Condena al enamorado a la soledad: el amor no puede concretarse y sólo puede existir como deseo" (Földenyi, 2008: 254). Y el deseo sólo existe cuando se carece de algo. Una vez saciado, ya no hay apetencia. Por eso, para eternizar el deseo, será siempre un amor insatisfecho que se retroalimentará con el sufrimiento. Ya no será como el amor cortés, en el cual, después de mucho sufrir, el amante obtenía la recompensa de verse amado por su dama; aquí no existe ni siquiera esa satisfacción. La dama llega a hacerse intocable desde un principio, o ha muerto, o está casada con otro hombre o se trata de una dama desdeñosa con el poeta. El gran padre de este dolce stil nuovo es Petrarca y su amada idealizada, Laura. En España, se encuentra Garcilaso sangrando versos para su espiritualizada Isabel Freire. Veamos el soneto XXV: "En poco espacio yacen los amores, / y toda la esperanza de mis cosas,/ tornados en cenizas desdeñosas/ y sordas a mis quejas y clamores" (I989:54). La melancolía surge de la visión de la amada como un ser al cual nunca se podrá acceder. El poeta se regodea en la idea del sufrimiento porque esta ansiedad hace nacer en él impulsos como el deseo y la creatividad.

No debemos dejar de señalar la melancolía amorosa en la obra cumbre de las letras hispánicas: Don Quijote. La locura amorosa en Gardenio, que termina dando fin a su propia vida, es un claro ejemplo. Y más interesante para nuestro análisis, el curioso impertinente, cuya enfermedad melancólica son los celos, al igual que la protagonista de Amistad funesta. Esta melancolía renacentista se tiñe de mayor dramatismo en el Barroco. Ciertamente, es en este periodo literario tan importante en las letras hispánicas donde se encuentra en casi todos los versos, sumergida, la experiencia profunda de la melancolía. Los grandes poetas Quevedo y Góngora van a poetizar el reverso de la ilusión amorosa: "Déjame en paz, amor tirano, /déjame en paz", de la letrilla gongorina, o del soneto de Quevedo que dice: "Aguarda, riguroso pensamiento, / no pierdas el respeto a cuyo eres". 
Volveremos a ver el fuerte efecto de la bilis negra en el Romanticismo, donde un joven como Werther (de Goethe) se encuentra sumido en un estado de locura melancólica por culpa de un amor no correspondido que le hace llegar al suicidio. Por su parte, el Modernismo muestra una gran influencia del Romanticismo en todo lo que respecta a la búsqueda del ideal, más concretamente, del ideal amoroso. Recoge, como señala Aníbal González (I987), además del decadentismo finisecular de Hysman, otros lugares comunes provenientes del Simbolismo. En esta coyuntura histórica de la crisis del fin de siglo, Miguel Ángel García nos muestra cómo es construida ideológicamente la subjetividad melancólica en el contexto de la Andalucía modernista, colocándola al lado opuesto al tópico de la "Andalucía romántica, colorista, pintoresca y exótica” (2OI2:I22).

\section{Amistad fiunestar bajo la maldición de la melancolía amorosa}

La historia que narra Martí es una historia de amor enfermizo y melancólico. Y tal como señala Rafael Ferreres, este amor "tan solo produce, al final, insatisfacción y melancolía” (I975:I77-I78). Lucía es una joven de fuerte carácter, enamorada de su primo Juan, hombre de gran valía humana que también se siente profundamente cautivado por la joven. Todo está en equilibrio hasta que aparece Sol, una hermosísima mujer por la que Lucía siente amor y odio a partes iguales. Lucía encarna el tema de la mujer fatal y del amor bilioso tan utilizado por el Modernismo y que Rafael Ferreres describe de esta forma: "Amor melancólico, amor triste, como esa música triste que querían fuese el modelo con el que identificar, fundir sus versos" (г975: г78).

Martí va a ir desgranando las características de estos personajes gracias a la simbología de ciertos objetos que muestran la personalidad de cada uno de ellos. Al comienzo de la novela, las tres jóvenes, Adela, Ana y Lucía se ven representadas por la flor que llevan en su vestido. En el caso de Lucía, el narrador señala que no llevaba flores en su vestido de seda carmesí: «porque no conocía aun en los jardines la flor que a ella le gustaba: ¡La flor negra!» (6). La referencia al color negro como tonalidad negativa es clara, al igual que el color del humor negro también tenía connotaciones maléficas. Ya Nerval incluía en sus versos otro nombre más poético para señalar la melancolía: hablaba del sol negro. Lucía da luz, pero son los rayos negros e irracionales de los que habla Nerval, los rayos que emanan del sol negro de la oscura bilis. Aparece Sol (como los rayos claros y fulgurantes del amanecer), la bella joven que surge unas páginas más adelante, y que romperá el equilibrio existente entre Lucía y su primo. El sol sigue presente cuando el narrador habla de otro objeto que caracteriza negativamente a Lucía: el sombrero. En el texto se señala que el sombrero "de Lucía era un sombrero arrogante y amenazador; se salían por el borde del costurero las cintas carmesíes, enroscadas sobre el sombrero de Adela como una boa sobre una tórtola: del fondo de seda negro, los reflejos de un rayo de sol” (8). Lucía es retratada como la mujer fatal, una mujer fuerte y dañina, como la serpiente que tentó a Adán en el paraíso y se enrosca, deslizándose hasta el hombre para 
traerle la desgracia. A. García ofrece una definición de lo que se entiende por mujer fatal en el Modernismo y otros ámbitos: "En términos muy generales, puede definirse como una mujer cuyo gran poder de fascinación provoca la destrucción o la muerte de uno o varios hombres" (2006:I78). El brazalete de perlas negras que adorna el brazo de Lucía constituye otro elemento muy significativo. Lucía le regala a Sol otro, un brazalete de perlas blancas. Comprobamos otra vez la misma antítesis cromática. Le pide que cierre los ojos y "los cerró Sol venturosa de verse tan querida por su amiga, y cuando los abrió, se vio en el brazo, e hizo por quitarse con un gesto que Lucía detuvo, un brazalete de cuatro aros de perlas margaritas" (75). El color blanco caracteriza a Sol ya que en ella todo es ingenuidad e inocencia. El reverso de la joven Sol es Lucía, la mujer fatal, y esto se demuestra en que posee la misma joya, pero las perlas, en vez de ser blancas, son negras: “¿ves? Yo tengo aquí otro, de perlas negras" (75).

Como se señalaba con anterioridad, existen ciertos rasgos melancólicos en la literatura como son el sentimiento de tristeza y de angustia por la amada o el amado desdeñoso o desdeñosa, o inaccesible. Freud hace referencia a que los melancólicos se torturan por algo que no ha ocurrido, es decir, por algo que se encuentra sólo en la mente del enfermo. Juan es descrito en todo momento como un hombre justo y honrado, pero Lucía, angustiada por los enfermizos celos, cree que está enamorada de Sol, aun cuando él nunca le ha dado motivos para sospechar. Ella duda de su prometido y se pone violenta también con Sol: "Pero, óyeme, a Juan tú no me lo quieras. Tú déjame a Juan para mí sola. Enójalo. Trátalo mal” (75). Todas las energías amorosas positivas son transformadas en odio. Freud también señaló que el amor y el odio forman parte del mismo sentimiento pero de signo contrario, por eso es fácil caer de un extremo al otro: "Porque te quiero, Juan, lo odio todo" (6o). El odio de la protagonista va aumentando a lo largo de la novela. La mujer fatal transforma el amor en odio y daña todo lo que se encuentra a su alrededor. Además, es una mujer sensual, de marcado erotismo, sobre todo en la poesía de Rubén Darío: "Él abre en la poesía española un acusado erotismo, arrebatado de sexualidad, como hacía siglos no se conocía en la lírica castellana” (R. Ferreres, I975:I75).

Uno de los textos clásicos que hacen referencia a la melancolía es Duelo y melancolía de Freud, escrito en I9I7. Anteriormente, K. Abraham ya "postula al sadismo como elemento primordial a raíz de las ideas freudianas que van preparando el terreno a Duelo y melancolía" (I. Sanfeliu, 2002:43). Este relevante ensayo de Freud se debe poner en relación al texto literario de Martí para tratar de profundizar en los aspectos que el psicoanalista subraya respecto a la enfermedad de la melancolía. El psicoanalista pretendía demostrar las diferencias entre el estado emocional del duelo y el de la melancolía. Como afirma I Sanfeliu, K. Abraham ya observará que la melancolía es una “forma arcaica de duelo" (2002:50). Freud señala que el duelo por la persona desaparecida aparecían ciertas similitudes al estado de melancolía, que hoy llamaríamos depresión. Pero la melancolía tiene rasgos propios que se pueden advertir en la actitud de la protagonista. La melancolía es un estado de ánimo profundamente doloroso. El sufrimiento en Lucía es constante: "A veces, te lo diré a ti sólo, sufro tanto que me tiendo en el suelo de mi cuarto, 
cuando no me ven, como una muerta" (6o). Se observa también una cesación del interés por el mundo exterior que comenta Freud, y en el caso de Lucía se hace más patente al final de la novela cuando se encierra en la habitación para no tener contacto con lo que le rodea. Otro de los síntomas es el desfallecimiento. Lucía se encuentra como alucinada, en estado de locura y casi sin fuerzas:

Y Lucía. Como alocada, hacía que no la oía. Le deshacía el peinado, le recogía el cabello a la manera que decía. - ¿Así? ¿No? Un poco más alto, que no te cubra el cuello. ¡Ah! ¿y las camelias?...¿Esas son? ¡Qué lindas son! Y la segunda vez dijo esto más despacio y lentamente como si las fuerzas le faltaran y se le fuera el alma en ello (94).

El último síntoma del que habla Freud es el de la disminución del amor propio. El enfermo se hace reproches y acusaciones a sí mismo. Siente deseo de comunicar a todo el mundo sus propios defectos y en este rebajamiento halla satisfacción. Este síntoma queda patente en Lucía cuando dice: “yo sé que no están en mí todas las hermosuras de la tierra, y como a ti te caben en el alma todas, y eres tan bueno que te he visto recoger las flores pisadas en las calles y ponerlas con mucho cuidado donde nadie las pise, creo, Juan, que yo no te basto" (6o). Según Freud las palabras de auto desprecio no van dirigidas contra sí mismo, en realidad los reproches van dirigidos a la persona amada. En este caso, Lucía está recriminando su actitud a Juan, aun cuando parezca que es ella la que insinúa la disminución de su amor propio. Esto puede ocurrir cuando el ser melancólico, señala Freud, hace la elección de la persona amada de una forma narcisista. En pocas palabras, elige a un ser que siente que se parece a su propia persona, es decir, ve el reflejo de sí mismo en él (mito de Narciso). Solamente cuando se hace esta elección puede el melancólico hacer la transferencia creándose un yo que vive en la persona y otro, ya hecho objeto, en el cual, el melancólico puede poner toda su rabia. Esta ambivalencia es la que permite en la novela la creación de un triángulo amoroso muy especial. Lucía, inconscientemente, ha absorbido en sí misma a Juan. Lucía y Juan son una sola persona. Por eso, existe esta ambivalencia amorosa. Lucía ve por los ojos de Juan, o lo que ella cree que ve Juan, y termina señalando como objeto amoroso a Sol: "Pero no era un hombre, no, el que con más insistencia, y un cierto encono mezclado ya de amor, miraba a Sol del Valle, y con dificultad contenía el llanto que se le venía a mares a los ojos, abiertos, en los que se movían los párpados apenas" (52). Este amor es secretamente correspondido por la bella Sol: "Lucía se había entrado por el alma de Sol, desde la noche en que le pareció sentir goce cuando se clavó en su seno la espina de la rosa. Lucía, ardiente y despótica, sumisa a veces como una enamorada, rígida y frenética enseguida sin causa aparente, y bella entonces como una rosa roja, ejercía, por lo mismo que no lo deseaba, un poderoso influjo en el espíritu de Sol” (67). La atracción que surge en la joven puede ser debida a su preferencia sexual por las mujeres o a ese carácter ambiguo que posee Lucía. Como señala Aníbal González: "Merece notarse la ambigüedad genérica que se sugiere en el 
personaje de Lucía; ella posee atributos tanto femeninos como masculinos, es un ser andrógino" (69). Sol parece estar atraída por esa parte dominante del carácter de Lucía. Por consiguiente, esta especie de desdoblamiento del yo hace posible que las tendencias sádicas y de odio hacia el objeto amoroso se vuelvan hacia el propio melancólico, de esta forma, el odio orientado hacia un objeto se retrotrae al yo del propio sujeto: "Erst dieser Sadismus löst uns das Rätsel der Selbstmordneigung, durch welche die Melancholie so interessant un so gefährlich wir" (Freud, 2OIO). La joven Sol llama a la puerta de Lucía: “¿Lucía no quiere abrirme! Yo creo que le pasa algo. La criada me dice que se ha vestido tres o cuatro veces, y ha vuelto a desvestirse, y a despeinarse, y se ha echado sobre la cama, desesperada, lastimándose la cara y llorando" (96). Lucía se autolesiona, se agrede a sí misma. Este sadismo, en muchas ocasiones, lleva al suicidio del melancólico, pero en este caso, Lucía asesina a Sol, su alter ego ideal. En vez de matarse a sí misma, mata a la mujer que le hubiera gustado ser. Sol, con los brazos abiertos, va a buscarla y ella coge la pistola: “Fuego! Y con un tiro en la mitad del pecho, vaciló Sol, palpando el aire con las manos, como una paloma que aletea, y a los pies de Juan horrorizado, cayó muerta” (96).

Juan es otro de los protagonistas más trascendentales de la novela dentro de este triángulo amoroso. Como vimos anteriormente, Martí habla de la personalidad de los personajes mostrándonos objetos que se encuentran en relación con ellos. Juan toma entre sus manos una taza cuyas asas son dos águilas, símbolo de inteligencia; además estos animales poseen una vista magnífica que les permite visualizar todo desde las alturas. Juan es un hombre majestuoso que se encuentra por encima de los demás, y gracias a su inteligencia y su vista, puede otear el mundo, verlo desde lugares superiores: "La bondad es la flor de la naturaleza. Aquel Juan brioso, que andaba siempre escondido en las ocasiones de fama y alarde, pero visible apenas se sabía de una prerrogativa de la patria desconocida o del decoro o albedrío de algún hombre hollados" (I2). Juan posee también cierto talante melancólico: la bilis negra del genio aristotélico. Los genios que tienen en su interior una cantidad mayor de humor negro gracias al cual están dotados de grandiosidad, también llevan el estigma del dolor. Señala el narrador: "Llevaba Juan Jerez en el rostro pálido, la nostalgia de la acción, la luminosa enfermedad de las almas grandes, reducida por los deberes corrientes o las imposiciones del azar a oficios pequeños; y en los ojos llevaba como una desolación" (Iо). Al referirse a la "enfermedad de las almas grandes" queda patente la relación con el genio de la melancolía aristotélica. El filósofo afirma en su obra El hombre de genio y la melancolía que tanto los grandes estrategas, como los filósofos y los artistas, y los seres especialmente dotados, poseían este genio que les hacía más propensos a enfermedades. Aristóteles se preguntó: “¿Por qué todos los que han sobresalido en la filosofía, la política, la poética o las artes eran manifiestamente melancólicos, y algunos hasta el punto de padecer ataques causados por la bilis negra, como se dice de Heracles en los (mitos) heroicos?” (953 $\left.{ }^{\mathrm{a}} \mathrm{IO}\right)$. No sólo Juan, existe otro personaje relacionado con las artes que posee un halo de negra bilis muy explícito. Se trata del pianista Keleffy: "Aquel dolor, que a veces con las manos crispadas se buscaba el triste músico por sobre el corazón, como para arrancárselo de raíz, aunque se tuviera 
que arrancar el corazón con él” (49). En la novela se hace referencia a la melancolía en la manera de tocar que posee Keleffy: "Aunque de una manera apesarada y melancólica y más de quien se aleja que de quien llega, tocó en el piano de madera negra” (50). Personajes como Juan y Keleffy personifican a los propios autores modernistas ya que estos se sienten poetas dotados de una especial sensibilidad unida a la tristeza modernista: "La nota o matiz predominante en todos los modernistas - y añadamos, de los que pasan por escritores del 98- es la melancolía. Todo es melancólico y los poetas y todos los poetas sienten el privilegio de ser agraciados con este estado de alta espiritualidad" R. Ferreres, I975:180).

Juan también puede ser analizado a la luz de la teoría antes señalada de Freud. En el duelo, afirma el psicoanalista, existe la pérdida real de un ser querido, sin embargo, en la melancolía, se siente la pérdida de algo que se desconoce, los melancólicos sufren pero no saben de dónde proviene la causa de dicho sufrimiento: "Y en otras circunstancias nos creemos autorizados a suponer una pérdida así, pero no atinamos a discernir con precisión lo que se perdió, y con mayor razón podemos pensar que tampoco el enfermo puede apresar en su conciencia lo que ha perdido" (Freud, 2OIO). Juan se encuentra en esta situación. Se cuestiona el porqué de su melancolía: "Siento a veces una melancolía dolorosa. ¿Qué me falta? La fortuna me ha tratado bien. Mis padres me viven. Me es permitido ser bueno" (57). Juan no acierta a encontrar una explicación racional a su tristeza y su abatimiento. Otros personajes importantes también padecen la pérdida del objeto a la que se refiere Freud. La enfermedad melancólica puede ser producida por la pérdida de un objeto amado pero, señala el padre del psicoanálisis, "en otras ocasiones, puede reconocerse que esa pérdida es de naturaleza más ideal” (Freud, 2OIO). En este caso se trata de la pérdida del amor por los ideales políticos. Por ejemplo, D. Juan Manuel, padre de Sol, enfermó de melancolía cuando vio que no pudo hacer realidad sus sueños al llegar a una nueva tierra, y que su vida se transformó en pesadumbre al encontrarse cargado de hijos y con una familia que alimentar: "Y como cuando la cestita le quemaba con más fuerza sentía él un poco paralizado el brazo del corazón, y todo el cuerpo vibrante como las cuerdas de un violín, y después de eso le venían de pronto unos apetitos de llorar y una necesidad de tenderse por tierra, que le ponía muy triste, aquel buen D. Manuel no veía sin susto como le iban naciendo tantos hijos" (33). Su mujer Andrea queda viuda, quedándose al cargo de toda su familia. El odio que siente esta mujer hacia el destino se observa en los celos que muestra (otra mujer fatal en la novela que transforma el amor en odio). Ella perdió su vida, perdió su juventud, sus oportunidades. Siente celos de su hija a la que se le abre un mundo nuevo gracias a su belleza: "Andaba siempre hablando consigo en voz baja, como si rezase; y otras regañaba por todo, ella que no regañaba antes jamás, pues lo que quería en realidad, sin atreverse, era regañar a Sol, de quien se encendía en celos y en miedos, cada vez que oía preparativos de fiesta o de paseo" (62). 


\section{Conclusiones}

En conclusión se puede decir que la melancolía gotea en cada línea de esta novela. Casi todos los personajes tienen cierto talante melancólico. Lo que la hace especial es la aparición del triángulo amoroso mortal formado por Juan, Sol y Lucía. La explicación freudiana ayuda a entender los avatares inconscientes que producen la muerte de Sol y también a comprender la atracción amorosa que surge de Lucía hacia la bella joven. En realidad, Sol y Lucía son la cara y la cruz de la misma moneda. Lucía, una mujer de carne y hueso, con temores, sentimientos que la perturban hasta enfermarla. Como puntualiza Aníbal González: "Lucía Jerez es un ejemplo de la "mujer histérica”, tan común en la ficción y en la psicología del siglo XIX y su historia es una especie de caso clínico (I987:69). Por su parte, Sol es el ideal, una mujer joven, inocente, de belleza fulgurante. Pero lo que Martí parece querer decir es que esa mujer ideal nunca se desarrollará porque la mujer real acabará por aniquilarla. La mujer vista por el hombre modernista tiene muy pocas opciones, o es una enferma o es un ser irreal. Por eso, como conclusión se puede señalar que el amor y la mujer son vistos, una vez más, desde la perspectiva del hombre, es decir, dentro de unos parámetros muy limitados y extremos. La enfermedad melancólica, o cuadro clínico, como la llama Aníbal González, queda impresa en el carácter de la mujer fatal tan característica en los textos modernistas; la voz de la mujer queda ensombrecida, despoblada de realidad, manipulada por sueños eróticos masculinos. 


\section{Bibliografía}

-Aristóteles. (2007). Elhombre de genio y la melancolía (problema XXX). Barcelona: Acantilado.

- Buonarroti, M. (20IO): Poema X. Obtenido el 27 de noviembre de 2010 desde http:/ /buonarroti-miguelangel.blogspot.com.

- De Góngora, L. (200o). Luis de Góngora. Madrid: Biblioteca Castro.

- De la Vega, G. (1989). Poesía completa. Madrid: Cátedra.

- De Rojas, F. (2000). La Celestina. Madrid: Cátedra.

- Freud, S. (2OIO). «Lo siniestro». Obtenido el 29 de noviembre de 2010 desde en http:// www.librosgratisweb.com/html/Freud-sigmund/lo-siniestro.

• Földényi, L. (2008). Melancolía. Barcelona: Galaxia Gutemberg.

- Hipócrates, (I996). Tratados hipocráticos. Madrid: Alianza Editorial.

- García, A. (2006). Fuentes del mito de la “mujer fatal” en El Ángel Azul (Der Blaue Engel, I930) de Josef Von Sternberg, Norla-Arte, 26, ISSN O2I3-22I4.

- García, M. (20I2). Melancolía vertebrada: La tristeza andaluza del Modernismo a la Vanguardia, Barcelona: Anthropos.

- González, A. (1987). La novela modernista hispanoamericana. Madrid: Editorial Gredos.

- Jackson, S. (1986). Historia de la melancolía y la depresión. London: Turner.

- Martí, J. (2OIO). Amistad funesta. Obtenido el 30 de noviembre de 2oio desde http:// www.edu.arg

- Litvak, L. (ed) (1975). El Modernismo. Madrid: Taurus Ediciones.

- Navarrete, C. (2006). Eros y Retórica: desde la locura Divina al Conocimiento Humano en Fedro de Platón. Espéculo: Revista de Estudios Literarios, 32, I80-I9o. ISSN-e II39-3637.

- Paul, A. (20I4). El concepto de melancolía en Marsilio Ficino. Eikasia: revista de filosofía, 57,I73- I86. ISSN-e I885-5679.

- Sanfeliu, I. (2002). Karl Abraham: El origen de la teoría de las relaciones objetuales, Frenia, 2. 